\title{
PÓS-MEMÓRIA E TRAUMA CULTURAL NA COTRADUÇÃO DE INFÂNCIA LISTRADA, DE BOGDAN BARTNIKOWSKI
}

\author{
Post-Memory and Cultural Trauma In The Co-Translation of "Infância \\ Listrada" (Dzieciństwo W Pasiakach) By Bogdan Bartnikowski
}

\author{
Eda NAGAYAMA \\ Universidade de São Paulo \\ eda.nagayama@gmail.com \\ https://orcid.org/0000-0001-5225-3585
}

\begin{abstract}
RESUMO: O artigo aborda o papel da afinidade e empatia na cotradução para o português brasileiro de Dzieciństwo $w$ pasiakach (1969), de Bogdan Bartnikowski para a editora do Museu AuschwitzBirkenau (Infância listrada, 2018), realizada em parceria com o Prof. Dr. Gabriel Borowski (Universidade Jaguelônica, Cracóvia, Polônia). Na obra em episódios, Bartnikowski (Varsóvia, Polônia, 1932) narra sua experiência, ainda criança, no campo de concentração de Auschwitz. A estrutura de transmissão traumática de pós-memória (Marianne Hirsch) é aqui utilizada, bem como os estudos de Trauma Cultural (Jeffrey Alexander), desdobramento multidisciplinar a partir do conceito de trauma nos Estudos da Cultura (Cathy Caruth). PALAVRAS-CHAVE: pós-memória; trauma; tradução; Holocausto.
\end{abstract}

\begin{abstract}
The article discusses the role of affinity and empathy in the co-translation with Prof. Dr. Gabriel Borowski (Jagiellonian University, Krakow, Poland) to Brazilian Portuguese of Dzieciństwo w pasiakach (1969) by Bogdan Bartnikowski for the publishing division of The Auschwitz-Birkenau Museum (Infância listrada, 2018). Throughout the book episodes Bartnikowski (Warsaw, Poland, 1932) narrates his experience as a child at the Auschwitz concentration camp. For this approach is used Marianne Hirsch's proposition of post-memory as a structure of traumatic transmission and Cultural Trauma understood by JeffreyAlexanderas amultidisciplinaryunfoldingafterthemigrationofthe concept of psychic trauma to the field of Cultural Studies (Cathy Caruth). KEYWORDS: postmemory; trauma; translation; Holocaust
\end{abstract}


Neste breve artigo proponho compartilhar questões que surgiram na experiência de cotradução de Dzieciństwo w pasiakach (Infância listrada, 2018), de Bogdan Bartnikowski (Varsóvia, Polônia, 1932), realizada em parceria com o Prof. Dr. Gabriel Borowski (Universidade Jaguelônica, Cracóvia, Polônia), sob encomenda da editora do Memorial e Museu Auschwitz-Birkenau. O livro é uma coletânea de episódios curtos, publicado pela primeira vez em 1969 (Nasza Księgarnia, Varsóvia), em que o autor relata a sua experiência, então um menino de 12 anos, como vítima e testemunha das condições do campo e da violência ali perpetrada. Para a reflexão, tomo a estrutura de transmissão de pós-memória proposta por Marianne Hirsch $(2008,2012)$ em diálogo com o âmbito cultural e social do trauma, suas representações e deslocamentos. No decorrer de sua investigação, Hirsch aventa a possibilidade de uma transmissão da memória que ocorra por identificação e afinidade, sem relação direta e vertical dos indivíduos com os sobreviventes e vítimas. Segundo essa perspectiva, os repertórios coletivos de um evento traumático como o Holocausto, sejam documentais, históricos ou artísticos, poderiam exercer um papel relevante e contundente para a valorização, apropriação e disseminação da memória, havendo o risco de contribuir para os estereótipos e distorções da ficcionalização e de usos político-ideológicos. Como relato testemunhal, o livro de Bartnikowski inscreve e traz à luz parte do vocabulário de excepcionalidade criado pela lógica e funcionamento do sistema concentracional nazista, do qual destaco aqui "torwacha", termo repetido em distintos episódios da obra, com potencial para atingir e ferir ao atuar como rastro e ressonância sintética e traumática dos repertórios individuais e coletivos do Holocausto.

\section{PÓS-MEMÓRIA AFILIATIVA}

Marianne Hirsch desenvolve seu trabalho teórico-analítico sobre a pós-memória partindo de sua experiência pessoal como membro da segunda geração de sobreviventes do Holocausto; sua família fora obrigada a deixar Czernowitz ${ }^{1}$, fugindo do nazismo e após a revogação dos direitos plenos de cidadania para os 100 mil judeus de cultura germânica que habitavam a localidade. Segundo as primeiras elaborações da autora (1997), a pós-memória seria caracterizada pela herança de narrativas e memórias moldadas por eventos traumáticos, mesmo anteriores ao nascimento do indivíduo, sentidas e percebidas como próprias, a ponto de se sobreporem à memória pessoal.

\footnotetext{
${ }^{1}$ Czernowitz foi a "Viena do Leste", capital de Bukowina, província do Império AustroHúngaro; atual Chernivtsi, no sudoeste da Ucrânia, próximo à fronteira com a Romênia.
} 
Posteriormente, Hirsch $(2008,2012,2019)$ deu ênfase à negação da pós-memória como movimento, método, ideia ou posição identitária, propondo seu entendimento como uma estrutura de transmissão geracional:

[...] a pós-memória não é uma posição identitária, mas uma estrutura geracional de transmissão integrada a múltiplas formas de mediação. A vida familiar, mesmo em seus momentos mais íntimos, está enraizada em um imaginário coletivo moldado por estruturas geracionais públicas de fantasia e projeção e por um arquivo compartilhado de histórias e imagens que modulam a transmissão da lembrança individual e familiar. ${ }^{2}$ (HIRSCH, 2012, p. 35, itálicos da autora, tradução nossa).

Apesar da opção da autora pelo termo, a "estrutura" aqui é marcada pelo dinamismo intrinsecamente vinculado à memória como matéria de subjetividade e afetada pelo transcorrer temporal, bem como pela proposição de transmissão que, por princípio, implica movimento e deslocamento de conteúdos entre sujeitos distintos. Segundo Hirsch, a geração de sobreviventes e vítimas legaria a experiência traumática a seus descendentes de modos diversos e concomitantes, nem sempre de posse de consciência ou intenção: direto, através de relatos orais; indireto, por meio de evidências materiais como fotos e objetos, ou de valores, hábitos e comportamentos; tal transmissão ainda poderia se dar como negatividade e vestígio, quando os conteúdos são silenciados, reprimidos e ocultados, ou revelados apenas de maneira fragmentária e parcial.

Se vista como forma de testemunho da experiência traumática, a estrutura de pós-memória traria em si o paradoxo da narração testemunhal ao se constituir como necessidade vital e parte da elaboração psíquica, ao mesmo tempo em que está submetida à dependência e insuficiência da linguagem, agravada pelo forte impacto emocional e aspecto afetivo, como aponta Cathy Caruth $(1995,1966)$. Em uma perspectiva de domínio invertido, a vítima seria então "possuída" por uma história que carrega dentro de si, mas sobre a qual não detém pleno entendimento ou propriedade, dificultando tanto o acesso, como a narrabilidade do evento para outro, estágio fundamental para assimilação e diminuição dos sintomas e sofrimento decorrente. Segundo a autora, essa contundência seria devida ao seu caráter literal - como síntese ou imagem -, em uma

\footnotetext{
${ }^{2}$ No original: “[...] postmemory is not an identity position but a generational structure of transmission embedded in multiple forms of mediation. Family life, even in its most intimate moments, is entrenched in a collective imaginary shaped by public, generational structures of fantasy and projection and by a shared archive of stories and images that inflect the transmission of individual and familial remembrance.".
} 
temporalidade que conjuga o tempo presente da repetição sintomática e o atraso em relação ao evento traumático original. Diante da falibilidade e lacunas da comunicação traumática parental, esse legado de pós-memória seria, para Hirsch, constituído assim de "emanações", fragmentos e flashes de eventos, condição em que a imaginação e os repertórios da segunda geração acabam preenchendo os vazios e atuando em prol de maior coesão e entendimento, necessários à identificação empática por parte dos descendentes. Em um desdobramento da proposição inicial, tal identificação e transmissão da memória poderia se dar por uma alteridade, sem que houvesse uma relação direta e familiar com a primeira geração de sobreviventes e vítimas, motivada por eletividade e afinidade associada à segunda geração:

A pós-memória afiliativa seria, portanto, o resultado de contemporaneidade e conexão geracional com a literal segunda geração, combinada com estruturas de mediação que seriam amplamente apropriáveis, disponíveis e, de fato, contundentes o suficiente para abranger um coletivo maior em uma rede orgânica de transmissão. ${ }^{3}$ (HIRSCH, 2008, p. 115, tradução nossa).

Conceber essa "rede orgânica de transmissão" é em especial pertinente no caso do Holocausto que, segundo Andreas Huyssen (2000), teria se tornado "globalizado" ao servir como uma espécie de prisma para a observação e análise de outros eventos e memórias traumáticas, deslocados espacial e temporalmente, como o genocídio em Ruanda e os massacres étnicos na antiga Iugoslávia. Em uma perspectiva convergente, Daniel Levy e Natan Sznaider (2002, 2006) afirmam que a "cosmopolização” da memória do Holocausto promoveria uma fertilização cruzada em que a força da memória coletiva global é alimentada e mantida pela interação com os significados e sensibilidades locais. Segundo os autores, a memória do genocídio judaico poderia assim adquirir relevância para uma identificação universalista e humanista, contribuindo para um discurso global de perdão e reconciliação que, em lugar de se basear em ética e moralidade absolutas, resultaria de embates e discussões locais da justiça no contexto de direitos humanos globalizados.

Em uma outra perspectiva, Jeffrey C. Alexander (2004) propõe que o Holocausto possa ser tomado como trauma cultural quando da percepção pelos membros de uma

\footnotetext{
${ }^{3}$ No original: "Affiliative postmemory would thus be the result of contemporaneity and generational connection with the literal second generation combined with structures of mediation that would be broadly appropriable, available, and indeed, compelling enough to encompass a larger collective in an organic web of transmission.".
} 
coletividade de submissão "a um evento terrível que deixa marcas indeléveis em sua consciência grupal, marcando suas memórias para sempre e modificando sua identidade futura de maneira fundamental e irrevogável"4 (2004, p. 1, tradução nossa). Tais marcas são carregadas de afeto negativo, sendo o evento considerado como ameaça para a própria existência do grupo ou como violação de um ou mais dos seus pressupostos culturais fundamentais. Neil J. Smelser (2004) destaca que o trauma cultural possa decorrer do reconhecimento de uma significativa responsabilidade moral pelo sofrimento humano causado pelo evento, em uma relação de solidariedade e compartilhamento. Segundo Alexander (2004), essa posição de empatia promoveria uma expansão do círculo de um "nós" na sociedade, em contraposição à restrição da dor traumática à esfera individual, ainda que sob o risco de acirrar circunscrições divisórias e disputas pelas narrativas traumáticas, em que cada um dos grupos envolvidos respondem e articulam uma memória ambivalente dos eventos: entre a compulsão para lembrar e a necessidade de esquecer, entre o apagamento para dirimir os danos e o reconhecimento e inscrição oficial dos traumas por meio de memoriais e espaços de memória. Nessa proposição de trauma cultural, a articulação temporal não seria de atraso entre evento original e repetição sintomática, como em Caruth, mas de triangulação já que a percepção no presente determina os efeitos do passado em marcas na consciência e em modificações futuras da identidade coletiva. E de maneira análoga ao trauma psíquico, para Alexander, o evento não seria inerentemente traumático, mas uma atribuição social mediada que poderia inclusive ocorrer de forma antecipada, como prenúncio, ou nem sequer ocorrer, impactando como algo imaginado.

O fenômeno de globalização, de deslocamento e apropriação coletiva das memórias do Holocausto, se daria então não apenas na esfera macro, de eventos traumáticos e narrativas étnicas e nacionais, mas também no âmbito individual e social, podendo adquirir assim a forma de pós-memória afiliativa, transmissão mediada pelos arquivos documentais e intensificada pelos crescentes repertórios culturais e artísticos, produção de variável grau de ficcionalização. $\mathrm{O}$ inevitável distanciamento temporal em relação ao Holocausto histórico impõe uma efetiva perda da possibilidade de legado direto da geração de sobreviventes e vítimas, fazendo com que a transmissão passe a ser necessariamente mediada, seja pelas gerações seguintes ou pelos arquivos e repertórios

\footnotetext{
${ }^{4}$ No original: "Cultural trauma occurs when members of a collectivity feel they have been subjected to a horrendous event that leaves indelible marks upon their group consciousness, marking their memories forever and changing their future identity in fundamental and irrevocable ways.".
} 
disponíveis. Nesse processo, os papeis do investimento imaginativo e da alteridade se tornam mais relevantes e significativos, acentuando o alerta para os riscos das distorções e manipulações de viés político e ideológico, tendo em vista o esperado afrouxamento do compromisso e rigor com a autenticidade e verdade da experiência original. Distintos da segunda geração, aqueles de pós-memória afiliativa se encontram mais livres para a observação e recriação, ao estarem isentos de um indissociável vínculo familiar; não sendo uma posição herdada, a afiliação enfatiza assim seu caráter performativo, em que a identificação pode ser experenciada como afeto subjetivo, mas descarregada de uma negativa inevitabilidade da origem familiar, cultural ou étnica.

\section{A COTRADUÇÃO DE DZIECIŃSTWO W PASIAKACH}

A tradução da obra de Bartnikowski adotou uma dinâmica de colaboração em etapas: uma primeira abordagem em que o texto em polonês foi traduzido para o português por Gabriel Borowski; seguida por minha contribuição, como escritora e falante de português brasileiro como língua materna, através de ajustes lexicais e reescritura visando coesão, fluência e adequação para o ponto de vista de um narrador ainda menino; e, por fim, uma última leitura conjunta para definição e escolhas mediante confronto com o original.

A versão após a primeira tradução detinha comentários e dúvidas de Borowski em relação ao entendimento do texto, bem como ao uso de termos e sua correspondência em português, mantendo então ainda alguns vocábulos no original, como no trecho do episódio Crianças ciganas (grifo nosso):

- Tenho um naco de pão, segura! - grito para o cigano no dia seguinte. Não há ninguém perto dos arames, só nos dois e aquela pequena, enfeitada com kokarda feita com um pedaço de atadura de papel. Zamachnałem się, jogo, mas não acerto, o cigano pula para lado como um gato, pega o pão, levanta para a boca, mas logo abaixa.

- Polonês, pega este pão. Eu não preciso.

— Está louco?! Hoje nos deram mais, toma, eu ainda tenho.

- Hoje para nosso bloco veio o lagerarzt. Tivemos que passar em frente dele, pelados, ao longo do bloco. Eu ouvi ele dizer: no final da tarde.

(...)

O cigano entrou por baixo do arame de morte e se aproximou da cerca.

— O que você está fazendo?! Cuidado! 
- Para mim tanto faz - responde, pegando os fios. - Está vendo? Estou vivo. Ela é pequena, ela passa fácil entre os arames. Leva ela... ${ }^{5}$

Além das esperadas dificuldades da tarefa de tradução, os campos de concentração nazistas, contexto original dos eventos narrados na obra, estabeleceram um léxico único e específico, baseado na língua alemã e sem equivalência ou precedente histórico, vinculado à sua lógica e funcionamento traumaticamente marcados. Esse socioleto do campo, o "lagerszpracha", seria uma convenção linguística completamente nova, segundo Danuta Wesołowska ${ }^{6}$ (apud BOROWSKI, 2019), servindo à desumanização das vítimas, mas que ao ser "polonizada", evidenciava-se como uma "necessidade vital dentro do campo, realia da existência concomitante não só em diferentes idiomas como entre idiomas, diante de crimes cuja extensão e crueldade os colocam fora da esfera da expressão linguística"7 (BOROWSKI, 2019, p.170, tradução e grifo nosso). No trecho, optou-se pela manutenção do termo "lagerarzt", com acepção em nota de rodapé ("médico alemão do campo de concentração"), de forma a manter o uso original do autor destacando assim as marcas do opressor também no léxico e comunicação cotidiana entre os prisioneiros de diferentes origens.

No episódio, Bogdan, o personagem-narrador, dialoga com outro interno, um menino cigano, cuja fala indicava sua alteridade e mimetizava a falta de pleno domínio da língua. Na versão final, buscou-se reproduzir esse efeito de estranhamento através do emprego de alguns verbos no infinitivo ("passar", "dizer”), a repetição do pronome

\footnotetext{
${ }^{5}$ No original:

“- Mam pajdkę chleba, trzymaj! - krzyknąłem do Cygana następnego dnia. Przy drutach było pusto, tylko my dwaj i ta mała, ustrojona w kokardę z kawałka papierowego bandaża. Zamachnąłem się, rzuciłem niecelnie, Cygan skoczył w bok jak kot, chwycił chleb, podniósł do ust, ale opuścił. - Polak, weź ten chleb. Mnie nie trzeba.

- Co ty!? Dziś dali nam dodatek, bierz, ja jeszcze mam.

- Dziś był u nas lagerarzt. Musieliśmy iść przed nim nago przez cały blok. Ja słyszałem, jak on powiedział - wieczorem.

(...)

Cygan wszedł pod drut śmierci i zbliżył się do drutów.

- Co robisz! Ostrożnie!

- Mnie wszystko jedno - odpowiedział, chwytając za przewody. - Patrz! Żyję. Ona mała, ona łatwo przejdzie między drutami. Weź ją...” (BARTNIKOWSKI, 2007, p. 63-64)

${ }^{6}$ Wesołowska D. Stowa z piekiet rodem. Lagerszpracha. Kraków: Impuls, 1996.

${ }^{7}$ No original: “...demonstrate the vital necessity within the camp realia of constantly existing not so much in different languages as between languages, in the face of crimes the extent and cruelty of which place them outside the sphere of linguistic expression."
} 
(“ela"), além da opção pelo uso de frases coordenadas, com quebra da fluência elocutória:

— Tenho um pedaço de pão, segura! — grito para o cigano no dia seguinte. Não há ninguém perto dos arames, só nós dois e aquela menininha, enfeitada com uma roseta feita com um pedaço de atadura. Tomo impulso e jogo, mas não acerto. $\mathrm{O}$ cigano pula para o lado como um gato e pega o pão. Ia levando à boca, mas para subitamente.

- Polonês, pega esse pão. Eu não preciso.

— Você está maluco?! Hoje nos deram um pouco mais, pega, eu ainda tenho.

- Hoje o lagerarzt veio ao nosso bloco. Andamos o bloco todo e também passar na sua frente. Pelados. Ele dizer: "no final da tarde". Eu ouvi.

(...)

O cigano passa por baixo do fio da morte e se aproxima da cerca.

- O que você está fazendo?! Cuidado!

- Para mim tanto faz — responde, pegando os fios. - Vê? Ainda estou vivo. Ela é pequena, ela passa fácil entre os arames. Leva ela... (BARTNIKOWSKI, 2018, p. 70, grifo nosso)

A percepção do léxico como rastro da violência e excepcionalidade do sistema concentracional nazista tornou-se mais acentuada ao longo do trabalho de cotradução, em que a recorrência de algumas palavras, mesmo em sua opacidade de não compreensão imediata, podiam carregar a "vaga sensação de algo letal, de palavras que continham esqueletos" (SCHWAB, 2006, p. 97). A autora propõe que tais palavras estejam relacionadas à "criptonímia", operações na linguagem que emergem como manifestações de uma cripta psíquica, em geral na forma de fragmentações, distorções, lacunas ou elipses. Originadas no silenciamento e encerramento do trauma, tais criptas poderiam ser individuais, bem como coletivas e até nacionais, encontrando assim convergência com a proposição de trauma cultural. Algumas palavras do universo lexical do Holocausto podem então ser emblemáticas do processo do trauma e sua transmissão ao estabelecerem uma potente dinâmica dupla: constituem-se como síntese de eventos repetidos, marcados por afetos negativos, ao mesmo tempo em que seu emprego repetitivo e sintético justamente acentua seu caráter traumático. Tal efeito não seria uniforme ou intrínseco às palavras, podendo se dar com termos cotidianos e constituído de modo subjetivo, como relata Nadine Fresco:

Há toda uma série de palavras que imediata, quase automaticamente, me fazem pensar nesse evento. Mesmo quando são palavras bastante comuns, como "vagão", "comboios", "gás", "estrela" e outras. Ou apenas a palavra "desaparecimento", que me faz pensar na morte nos campos. No rádio, há algum tempo, um jornalista estava explicando que a vacinação contra varíola não era mais obrigatória, porque a varíola havia desaparecido. Deus sabe que havia todas as razões para achar que esse desaparecimento 
em particular fosse uma coisa muito boa. Mas quando ele disse isso, senti uma espécie de angústia pela ideia de que não existia mais, que nunca mais existiria e que um dia não se saberia mais o que teria sido - e talvez nem mesmo que tivesse desaparecido. ${ }^{8}$ (FRESCO, 1984, versão online, tradução nossa)

De forma distinta à de Fresco, no trabalho sobre Bartnikowski o afeto negativo foi gerado não por palavras conhecidas e até cotidianas que têm sua utilização deslocada e alterada de forma violenta e excepcional pelo Holocausto, mas por vocábulos opacos e herméticos que só adquiriram sentido no transcorrer do trabalho tradutório. Tomo aqui como exemplo o termo "torwacha", distorção do alemão "Torwache" ("porteiro"), neologismo que surge no contexto dos campos de concentração nazistas e se referia ao prisioneiro cuja função era vigiar a entrada do bloco. Detentor de um exíguo poder sobre os demais, era frequente o uso de brutalidade e violência verbal e física pelo torwacha que, ao longo de Infância listrada, se não é configurado diretamente, aparece sob a forma de latência e temor, como em sua primeira ocorrência, em Tapete:

Tenho sede... Mas não desço do beliche. Para que apanhar na cara do torwacha que está à porta? E no barracão não tem mesmo nada para beber. Tenho que aguentar até de manhã. Ouço a respiração profunda das crianças que dormem ao meu redor. Elas se mexem, empurram e se coçam sem parar. Seus corpos brilham na penumbra, brilham de marrom, de vermelho, como um arco-íris. ${ }^{9}$ (BARTNIKOWSKI, 2018, p. 22, grifo nosso)

Através dos relatos episódicos, o autor gradualmente introduz o leitor nas condições e ambiente dos barracões dos menores no campo de Auschwitz; aqui, o brilho dos corpos,

\footnotetext{
${ }^{8}$ No original: "There's a whole series of words, which, immediately, almost automatically, make me think of that event. Even when they are quite ordinary words, like "wagon", "convoys", "gas", "star", and others. Or just the word "disappearance", which makes me think of their death in the camps. For example, some time ago, on the radio, a journalist was explaining that anti-smallpox vaccination wasn't obligatory anymore, because smallpox had disappeared. God knows that there was every reason to think that that particular disappearance was a very good thing. But when he said that, I felt a kind of distress at the idea that it no longer existed, that this thing would never exist again, and that one day one would no longer know what it had been--and perhaps even that it had disappeared."
}

${ }^{9}$ No original: "Pić... Ale nie zejdę z pryczy. Po co mam dostać po gębie od wachy przy drzwiach. A przecież w baraku nie ma nic do picia. Muszę jakoś wytrzymać do rana. Wokół głęboko oddychają śpiące dzieciaki. Rzucają się, odpychają, drapią się zawzięcie. Ciała ich połyskują w półmroku, połyskują brązowo, czerwono, jak tęcza." (BARTNIKOWSKI, 2007, p.20) 
na imagem inicial de um arco-íris no meio da noite, revela-se como infestação, "tapete" de percevejos que cobrem as crianças e sugam-lhes o sangue. A mesma apreensão em relação ao torwacha e uma rotina de violência é reiterada em outro episódio, "Pai e filhos", quando o caçula de dois irmãos faz referência à casa da família em contraposição às condições no campo, reclamando do reduzido espaço por causa do compartilhamento de camas, das goteiras:

— Agora?! À noite?! Se um homem da SS vir você, vai te matar a tiro! Aliás, o torwacha não vai te deixar sair do bloco. Dorme!

— Mas aqui está tão apertado...

- Você vai acabar acordando todo mundo e vão nos bater. Como ontem. Isto aqui não é como em casa...

— Não... - suspira Jacek. — Em casa eu tinha uma cama só pra mim. E não pingava. Quando formos para casa, eu vou voltar a dormir sozinho, como antes.

— Não sei... Você viu que os alemães queimaram a nossa casa.

Casa... Não tem um só dia em que não lembramos dela. Pensando bem, por quê? Vimos nossas casas queimarem e sabemos que, mesmo antes, já eram só destroços. Mas ainda assim, continuamos a dizer: nossa casa, em nossa casa, para nossa casa.

- A cama queimou também?

— Tudo. Você não viu? Agora acabou, não tem como dormir mais. $\underline{\mathrm{O}}$ torwacha já está se levantando, daqui a pouco vai tocar o sino... A gente precisa levantar. ${ }^{10}$ (BARTNIKOWSKI, 2018, p. 98, grifo nosso)

Para o irmão menor, o consolo de uma volta à normalidade e ao lar pode ser reduzido apenas à sua cama familiar que, no entanto, é também uma impossibilidade até para ser almejada, se a casa fora queimada pelos alemães. Para Bogdan em Bombardeio, a satisfação não pode ser alcançada nem mesmo em sonho, quando o menino desperta

\footnotetext{
${ }^{10}$ No original: “- Teraz?! W nocy?! Jeśli esesman cię zobaczy, zaraz zastrzeli! A i torwacha nie wypuści cię z bloku. Śpij!

- Kiedy tak ciasno...

- Obudzisz wszystkich i pobiją nas. Jak wczoraj. Tu nie dom...

- Nie... - westchnął Jacek. - W domu miałem swoje łóżko. I nie kapało. Jak wrócimy do domu, będę znów spał sam, jak dawniej.

- Nie wiem. Widziałeś, że dom spalili nam Niemcy.

Dom... Nie ma dnia, by nie wracać doń myślami. Właściwie dlaczego? Widzieliśmy, jak płonęły nasze domy, wiemy, że nim spłonęły, były już tylko ruinami. A jednak wciąż mówimy - nasz dom, w naszym domu, do naszego domu...

- I łóżko też się spaliło?

- Wszystko. No i widzisz, już po spaniu, torwacha wstaje, zaraz będzie dzwon, już... Trzeba wstawać." (BARTNIKOWSKI, 2007, p. 88)
} 
após desaparecerem os pães que saciariam o perene estado de fome comum a todos. Em meio ao silenciamento e escuridão da realidade no interior do bloco infantil, a brutalidade se faz presente mesmo em negatividade, quando faz menção aos sons normalizados e cotidianos que, naquele momento, não são ouvidos - os roncos e soluços, os insultos do torwacha:

Levanto as pernas ainda mais um pouco e corro mais rápido, mais rápido. A loja com a vitrine cheia de pães está bem perto. Já, já vou poder tocar... Mas o que aconteceu? Algo se crava em meu crânio, o pão desaparece, não vejo mais, não tem mais nada, nenhum pão...

Abro os olhos. O bloco está em silencio, não se ouvem os roncos e soluços, os insultos que o torwacha costuma lançar contra os pirralhos sonolentos que vagueiam pelo bloco porque foram para a latrina e não sabem voltar para seus beliches. (...) O campo está imerso na escuridão, à espreita, esperando de respiração suspensa. Mesmo assim, algo continua a denunciá-lo, ainda agora. Em meio ao breu da noite, as únicas luzes no campo são as colunas vermelhas de fogo cuspidas pelas chaminés do crematório. ${ }^{11}$ (BARTNIKOWSKI, 2018, p. 135, grifo nosso)

Como respiração que não pode ser suspensa mais do que por um breve intervalo, a negatividade do campo é logo atestada pelas "colunas vermelhas de fogo cuspidas pelas chaminés do crematório", a aviltante e inaceitável operação que não cessa, mesmo no silêncio da noite. Tal imersão no ambiente concentracional dos relatos de Bartnikowski apresenta momentos de maior agudez, quando instâncias como arbitrariedade, vitimação da infância e um desdobramento desfavorável são então sobrepostas, como ocorre em Crianças ciganas:

— Rápido! — olho para a torre de guarda — O SS não está vendo. Agora! - apresso.

Cuidadosamente, a menina enfia o pezinho entre os arames. O cigano levanta um fio, pisa o outro, mais um instante e a ciganinha já está junto ao poste, entre as filas de espinhos. Atravesso a faixa da morte com um

\footnotetext{
${ }^{11}$ No original: "Jeszcze odrobinę wyżej podciągnąć nogi, prędzej biec, jeszcze prędzej, sklep i witryna pełna chleba jest już blisko, już, już go dotykam... Ale co to? Coś wwierca się w czaszkę, chleb niknie, nic już nie widzę, nie ma, nie ma chleba...

Otworzyłem oczy. W bloku jest cicho, nie słychać zwykłych chrapań, popłakiwań i przeklinań torwachy na zaspanych, błąkających się po bloku malców, którzy poszli do kibla i nie mogą z powrotem trafić na swoje prycze. (...) Obóz utonął w mroku, przyczaił się, wstrzymał oddech i czeka. No nie, coś go przecież zdradza, nawet teraz. Czerwone słupy ognia nad kominami krematorium, to teraz jedyne światła w czerni nocy." (BARTNIKOWSKI, 2007, p. 119).
} 
salto e estendo a mão na sua direção. Só mais um pouquinho e ela já estará do nosso lado dos arames. Só mais um pouquinho...

Uma crepitação rápida. A menina nem sequer gritou e, de repente, encolheu, ficou completamente negra. A fumaça e o fedor de carne queimada se espalharam no ar, como uma pequena nuvem, na minha direção.

- Ligaram... Ligaram... - sussurro, sem conseguir tirar os olhos daquilo que sobrou dela. - Ligaram... ${ }^{12}$ (BARTNIKOWSKI, 2018, p. 71)

O incidente pode ser tomado como representativo do afeto negativo intrínseco ao próprio Holocausto, ao ressoar e dialogar com os repertórios documentais e históricos, bem como os artísticos e ficcionais. A excepcionalidade e ineditismo são aqui singularizados pelo corpo de uma criança eletrocutada pela cerca elétrica de um campo de concentração, evento também pertencente ao âmbito do inimaginado e impossível até sua ocorrência, como aponta Bauman (1998) em relação ao genocídio judaico. Em outra perspectiva, é marcante nessa cena de "Crianças ciganas" a separação entre causa e efeito, característica ao Holocausto como procedimento moderno e fragmentado, em que os efetivos agentes da violência não estão presentes nem contemplam as consequências das operações do sistema, isentos de qualquer responsabilidade imediata e direta. Se acaso a morte da menina cigana fosse presenciada por um nazista, a culpabilidade recairia sobre o irmão, jamais sobre um sistema moralmente neutro, de "consequências imprevistas" e "resultados não intencionais", em que os prisioneiros pertencem a categorias desprovidas de demandas morais, sem "rosto", quando "o impacto limitador da responsabilidade moral pelo Outro é suspenso e tornado ineficaz" (BAUMAN, 1998, p. 168).

A exclusão dessa alteridade destituída de "rosto" e da relação de causalidade entre ação e consequências promove a neutralização do impacto destruidor e desregulador do comportamento moral, sem abraçar ou patrocinar o mal propriamente dito, mas sem tampouco fomentar o bem, tornando "a ação social sem esforço, adiaforética

\footnotetext{
${ }^{12}$ No original: “- Prędko! - spojrzałem na wieżyczkę strażniczą. - Posten nie patrzy, teraz! ponaglałem.

Ostrożnie wsunęła nóżkę między druty. Cygan uniósł jeden drut, stopą nacisnął drugi, jeszcze chwila i mała znalazła się tuż przy słupie, między rzędami kolców. Przeskoczyłem przez pas śmierci, wyciągnąłem rękę do małej, jeszcze chwila, już była między drutami po naszej stronie, jeszcze chwila...

Zaskwierczało, nawet nie krzyknęła, sczerniała nagle, zmalała, dym i swąd spalonego ciała przepłynął obłoczkiem ku mnie.

- Włączyli... włączyli... - szeptałem, nie mogąc oderwać oczu od tego, co z małej zostało. Włączyli... (BARTNIKOWSKI, 2007, p. 65)
} 
(originalmente, adiaphoron era uma coisa declarada indiferente pela Igreja) - nem boa nem má, mensurável por padrões técnicos (voltados para um propósito ou processuais) mas não por valores morais" (BAUMAN, 1998, p. 168, itálicos no original). De modo correspondente, o socioleto do nazismo no contexto dos campos de concentração não é por si mesmo bom ou mau, mas de predomínio técnico e descritivo, relacionado às funções e posições de comando, cujas variantes foram firmadas pelo uso corrente por parte dos não falantes do alemão. Em Infância listrada, o emprego desse léxico conjugado às circunstâncias narradas acaba por moralmente municiá-lo de modo a provocar um impacto de afeto negativo, ainda intensificado pelas repetições em diferentes episódios. Como exemplo, utilizei aqui "torwacha", mas há outros termos, como "sztubowy", prisioneiro responsável pela ordem em um dos compartimentos do barracão (sztuba, do alemão Stube); "Blockführer, "líder do bloco" em alemão; "Häftling”, "prisioneiro" em alemão; "aufzejerka”, supervisora das prisioneiras no campo de concentração (do alemão Aufseherin); "szajskomando", grupo de prisioneiros com a função de levar recipientes com excrementos para fora do bloco (do alemão Scheisskommando).

A carga moral adquirida por esse universo lexical excepcional pode ser vista como decorrência e rastro de uma transmissão de memória traumática que, como propõe Hirsch, poderia atingir indivíduos mesmo que não detivessem relação geracional direta com sobreviventes e vítimas do Holocausto. Nesse trabalho de tradução da obra de Bartnikowski, posso afirmar que houve de minha parte um efetivo empenho voltado para uma posição de afinidade e identificação, ainda que delimitada por inerente alteridade identitária e deslocamento espaçotemporal. Passados vários meses após a finalização do trabalho e envio dos originais, a seção editorial do Memorial e Museu Auschwitz-Birkenau remeteu então a prova para uma última revisão antes da impressão da tiragem. O retorno ao texto, em especial a esse referido léxico, ao mesmo tempo estranho e familiar, evidenciou seu potencial para ainda ferir, como vestígio do afeto negativo provocado anteriormente pela imersão na tradução dos episódios, bem como pelas remissões e reminiscências dos inumeráveis relatos e imagens que integram os repertórios individuais e coletivos sobre o Holocausto. Tal percepção do retorno à obra como negatividade pode assim remeter à cripta psíquica de Schwab que, no caso do Holocausto, seria não apenas traumática, mas vasta, coletiva e globalizada. Esse violento vislumbre daquilo que permanece oculto e silenciado na cripta traumática pode ser identificado em outras narrativas, com uso de linguagens distintas. Em Maus, graphic novel de Art Spiegelman, originalmente publicada em episódios entre 1980 a 1991, o autor recria imaginativamente a operação "normal" do campo (Figura 1, à esquerda), revivificando a entrada principal de Auschwitz I, tomando por base imagens do portão, sejam as históricas ou de sua réplica (Figura 1, à direita). 

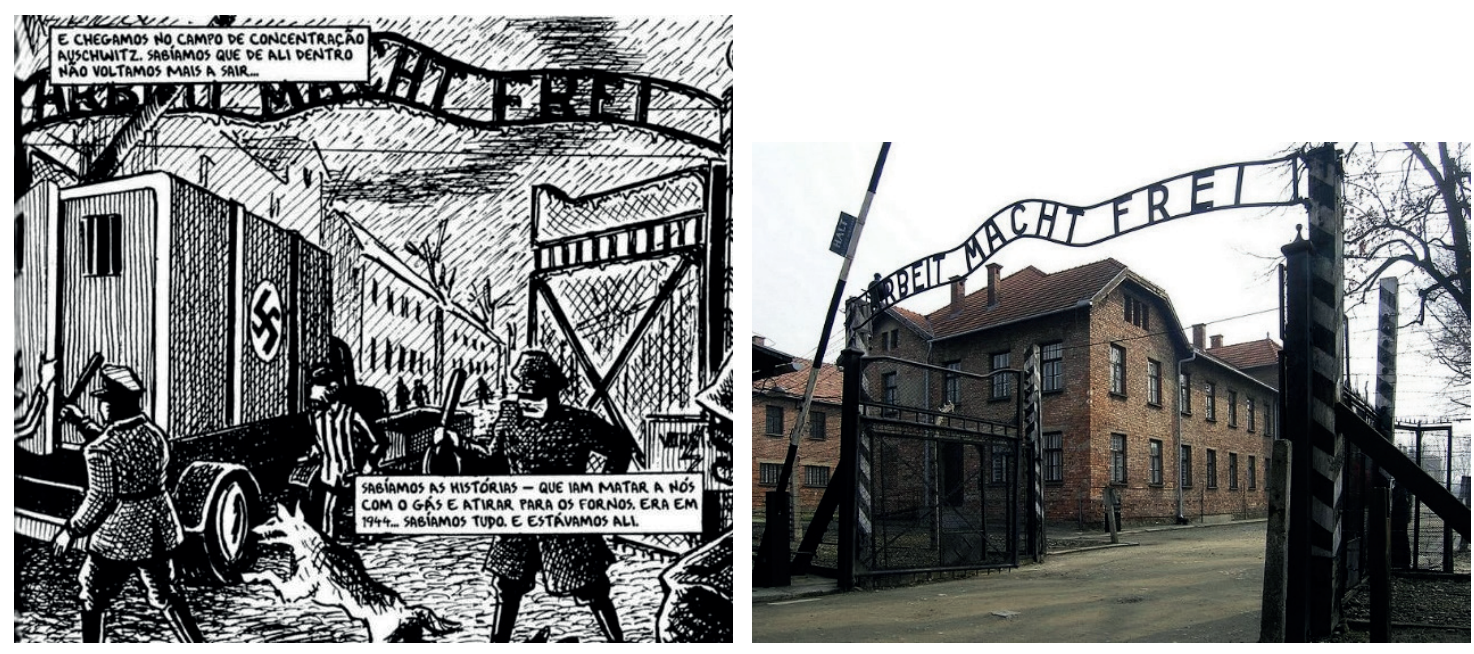

FONTES: SPIEGELMAN (2005), DNALOR 01 (2007).

O potencial de opressão psíquica das imagens documentais é utilizado em outro trecho de Maus para configurar o próprio questionamento de Spiegelman em relação às edições traduzidas no exterior e ofertas de adaptação para TV ou filme (Figura 2, à esquerda), evidenciando o impositivo fardo da herança de filho de sobreviventes, elemento intrínseco à pós-memória como estrutura de transmissão geracional do trauma, segundo Hirsch. A contundência da imagem original (Figura 2, à direita) agudiza o dilema ético e moral do autor: a experiência traumática individual, familiar e coletiva, de milhões de vítimas e sobreviventes, sob o risco de banalização e massificação ao transformá-la em produto de consumo de massa, destinado a incontáveis outros, maioria sem vínculo ou lastro com os acontecimentos passados para além de interesse e afinidade temática.

$\mathrm{O}$ receio de Spiegelman se realizou de maneira exacerbada e ultrajante em produtos que chegaram a ser comercializados pela gigante global Amazon ${ }^{13}$ no final de 2019. Retirados após repercussão negativa internacional e protestos do Memorial e Museu Auschwitz-Birkenau, produtos variados, como mousepad, abridor de garrafas, enfeites de Natal e mesmo uma toalha de praia, utilizavam imagens emblemáticas do complexo concentracional Auschwitz-Birkenau: o portão de entrada com a inscrição

\footnotetext{
${ }^{13}$ Imagens disponíveis nos posts do Twitter do Auschwitz Memorial (@AuschwitzMuseum): $<$ https://twitter.com/auschwitzmuseum/status/1201583746719322114> e <https://twitter.com/ AuschwitzMuseum/status/1201069830553649153>. Acesso em 12 jun.2020.
} 
“Arbeit Macht Frei”, os trilhos e o portão principal de Auschwitz II-Birkenau, as cercas de arame farpado em Auschwitz I.

FIGURA 2 - ILUSTRAÇÃO DE MAUS, VERSÃO ORIGINAL EM INGLÊS (À ESQUERDA); CORPOS AMONTOADOS, FOTO TIRADA APÓS A LIBERTAÇÃO DO CAMPO DE CONTRAÇÃO DE DACHAU, ALEMANHA, PELO EXÉRCITO DOS ESTADOS UNIDOS (À DIREITA)
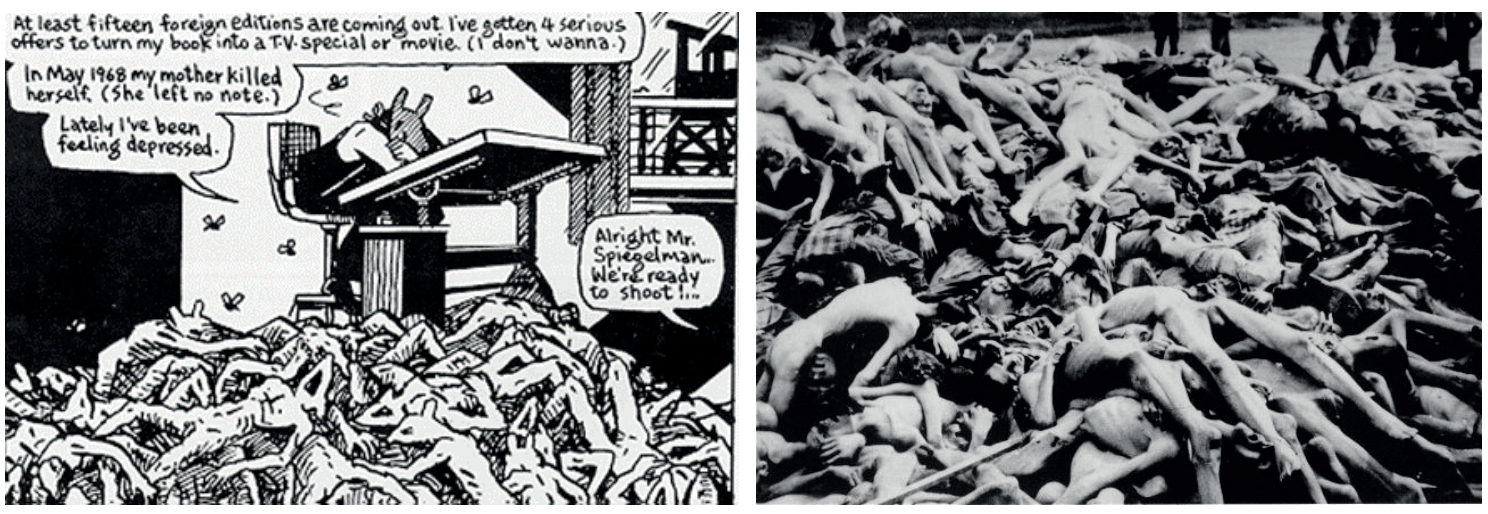

FONTES: SPIEGELMAN (1996), LANDGREN (1945).

FIGURA 3 - PRODUTOS ILUSTRADOS COM IMAGENS DO CAMPO DE AUSCHWITZ QUE CHEGARAM A SER COMERCIALIZADOS PELA AMAZON: TOALHA DE PRAIA (À ESQUERDA), DECORAÇÃO DE NATAL (À DIREITA)
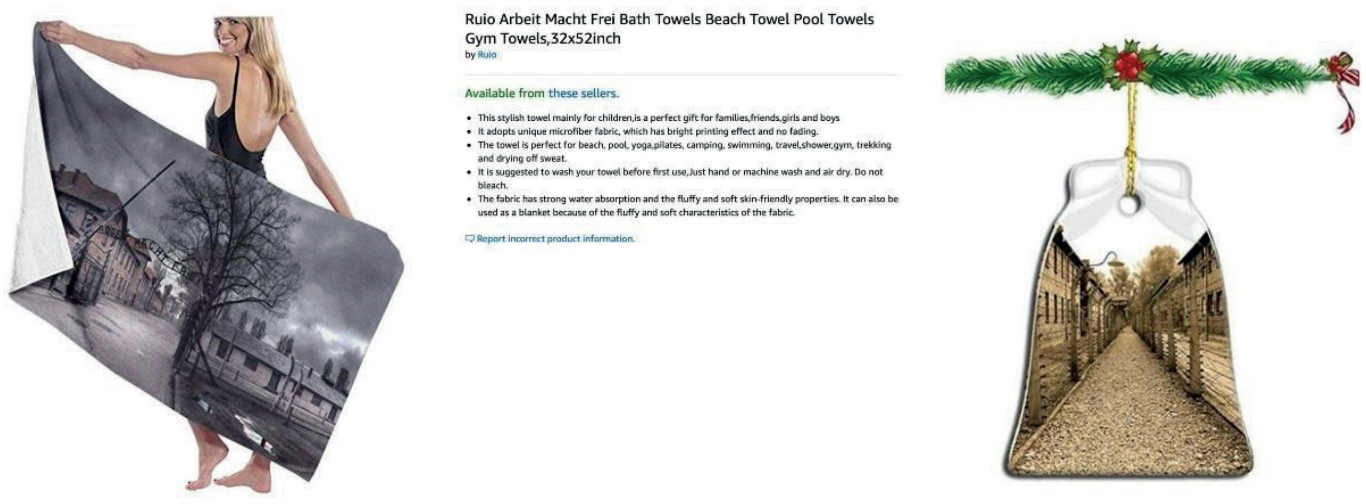

FONTES: SOMMER (2019), WEICH (2019) 
A idealização e fabricação de tais produtos atestam a incorporação do genocídio pela cultura de massa e de consumo que reconhece e adota Auschwitz como ícone e representação, mas também estabelece uma ampla dissociação e indiferença moral em relação aos acontecimentos, contextos e vítimas, cenário que se torna mais grave e alarmante diante do crescimento contemporâneo de tendências autoritárias e populistas, como se verifica no Brasil, bem como nos Estados Unidos, Filipinas, Hungria e Polônia. Se no passado, a alteridade indesejável dos "gatos" nazistas foram os "ratos" judeus, como figurados por Spiegelman, no presente são os migrantes e refugiados, bem como aqueles diversos religiosa e etnicamente, ou de forma genérica, os mais precários e vulneráveis da economia global, os "redundantes", nos termos de Bauman (2017).

\section{CONSIDERAÇÕES FINAIS}

Na experiência de cotradução de Infância listrada, o desdobramento aventado por Hirsch de transmissão de pós-memória traumática em uma vertente afiliativa, se mostrou possível e pertinente, consideradas as demandas dessa tarefa específica de obrigatória e reiterada imersão nas cenas e acontecimentos, de adoção e identificação com o ponto de vista adotado pela narrativa. Em diálogo com o repertório individual e coletivo do Holocausto, os episódios de Bartnikowski acabaram por constituir um inesperado impacto de negatividade que conjuga temporalidades pretéritas e presentes, bem como a subjetividade de vítima e sobrevivente que se sobrepõe à pessoal da cotradutora, como alteridade em relação à obra - ampla, se também cultural, nacional e étnica. Se "torwacha" é vocábulo com qualidade para ferir, é por ainda remeter à cripta traumática e ressoar sua origem nos inaceitáveis sistemas de exceção criados pelo nazismo. Reafirmando as proposições de Huyssen e de Levy e Sznaider do Holocausto como evento cosmopolita e prisma para a observação da contemporaneidade, "torwacha" se torna indicial da necessidade de que a violência do passado ainda seja capaz de nos afetar e indignar, de nos alertar acerca dos riscos da indiferença moral e dos abismos abertos entre "nós" e "outros", da dissociação entre causas, consequências e responsabilidades pelos atos e escolhas individuais e coletivas - sempre.

\section{Agradecimentos}

Ao Prof. Dr. Gabriel Borowski pela confiança e parceria na cotradução de Infância listrada. Veementemente recomendo a leitura de seu artigo sobre a mesma experiência, muito pertinente e enriquecedora na perspectiva dos estudos tradutológicos. 


\section{REFERÊNCIAS:}

ALEXANDER, Jeffrey C. Toward a theory of cultural trauma. In: ALEXANDER, Jeffrey C. et al. Cultural trauma and collective identity. Berkeley/Los Angeles/Londres: University of California Press, 2004, p. 1-30.

BAUMAN, Zygmunt. Estranhos à nossa porta. Rio de Janeiro: Zahar, 2017.

BAUMAN, Zygmunt. Modernidade e Holocausto. Rio de Janeiro: Zahar, 1998.

BARTNIKOWSKI, Bogdan. Dzieciństwo w pasiakach. Oświęcim: Państwowe Muzeum Auschwitz-Birkenau w Oświęcimiu, 2007.

BARTNIKOWSKI, Bogdan. Infância listrada. Trad. Gabriel Borowski, Eda Nagayama. Oświęcim: Państwowe Muzeum Auschwitz-Birkenau w Oświęcimiu, 2018.

BOROWSKI, Gabriel. It Gives You Shivers: Translating Polish Holocaust Testimony into Brazilian Portuguese. Przekładaniec, special issue, "Translation and Memory", 2019, p. 157-174. Disponível em: <www.ejournals.eu/Przekladaniec>. Acesso em 12 jun. 2020.

CARUTH, Cathy. Unclaimed experience: trauma, narrative and history. Baltimore: The Johns Hopkins University Press, 1996.

CARUTH, Cathy. (ed.). Trauma: explorations in memory. Baltimore: The Johns Hopkins University Press, 1995.

DNALOR 01. Auschwitz I Camp, Main Gate, Arbeit macht frei, Oswiecim, Poland. 10 mar. 2007. 1 fotografia. Disponível em: <https://commons.wikimedia.org/wiki/ File:Eingangstor_des_KZ_Auschwitz,_Arbeit_macht_frei_(2007).jpg>. Acesso em 12 jun. 2020.

FRESCO, Nadine. Remembering the Unknown. Translated from the French by Alan Sheridan. International Review of International Review of Psycho-Analysis, Londres, v. 11, 1984. p. 417-428. Disponível em: <http://www.anti-rev.org/textes/Fresco84a/>. Acesso em 12 jun. 2020.

HIRSCH, Marianne. Connective arts of postmemory. Analecta Política, Medellín, v. 9, n. 16, 2019, p. 171-176.

HIRSCH, Marianne. Family frames: photography, narratives, and postmemory. Cambridge: Harvard University Press, 1997. 
HIRSCH, Marianne. The generation of postmemory. Poetics Today, Durham, v. 29, n. 1, 2008, p. 103-128.

HIRSCH, Marianne. The generation of postmemory: writing and visual culture after the Holocaust. Nova York: Columbia University Press, 2012.

HUYSSEN, Andreas. Seduzidos pela memória: arquitetura, monumentos, mídia. Rio de Janeiro: Aeroplano, 2000.

LANDGREN, William. [A pile of corpses lies on the ground in the newly liberated Dachau concentration camp]. 29 abr. - 01 maio 1945. 1 fotografia, p\&b. Disponível em: $<$ https://collections.ushmm.org/search/catalog/pa31195>. Acesso em 12 jun. 2020.

LEVY, Daniel; SZNAIDER, Natan. Forgive and not forget: reconciliation: between forgiveness and resentment. In: BARKAN, E.; KARN, A. Taking wrongs seriously: apologies and reconciliation. Stanford: Stanford University Press, 2006, p. 83-100.

LEVY, Daniel; SZNAIDER, Natan. Memory unbound: The Holocaust and the formation of cosmopolitan memory. European Journal of Social Theory, Londres, v. 5, n. 1, 2002, p. $87-106$.

SCHWAB, Gabriele. Writing against Memory and Forgetting. Literature and Medicine. Baltimore: Johns Hopkins University Press, v. 25, n. 1, Spring 2006, p. 95-121.

SMELSER, Neil J. Psychological Trauma and Cultural Trauma. In: ALEXANDER, J. C. et al. Cultural trauma and collective identity. Berkeley/Los Angeles/Londres: University of California Press, 2004, p. 31-59.

SPIEGELMAN, Art. Maus. Nova York: Pantheon, 1996.

SPIEGELMAN, Art. Maus. São Paulo: Companhia das Letras, 2005.

SOMMER Allison Kaplan. Why Auschwitz Christmas Ornaments and Birkenau Bath Towels Won’t Go Away Anytime Soon. Haaretz, Tel Aviv, 05 dez. 2019. Disponível em: $<$ https://www.haaretz.com/us-news/.premium-amazon-auschwitz-christmas-ornamentsbirkenau-bath-towels-1.8224360>. Acesso em 12 jun. 2020.

WEICH, Ben. Amazon pulls 'Auschwitz-themed Christmas decorations'. The Jewish Chronicle, Londres, 02 dez. 2019. Disponível em: <https://www.thejc.com/news/world/ amazon-auschwitz-holocaust-themed-christmas-decorations-ornaments-1.493778>. Acesso em 12 jun. 2020. 